\title{
Effects of SCH-23390 in Combination with a Low Dose of $17 \beta$-Estradiol on Anxiety-Like Behavior in Ovariectomized Rats
}

\author{
Julia Fedotova \\ Laboratory of Neuroendocrinology, I. P. Pavlov Institute of Physiology of the Russian Academy of Science, \\ 6 Emb. Makarova, Saint Petersburg 199034, Russia \\ Correspondence should be addressed to Julia Fedotova; julia.fedotova@mail.ru
}

Received 25 April 2013; Revised 29 December 2013; Accepted 19 January 2014; Published 23 February 2014

Academic Editor: George Perry

Copyright (c) 2014 Julia Fedotova. This is an open access article distributed under the Creative Commons Attribution License, which permits unrestricted use, distribution, and reproduction in any medium, provided the original work is properly cited.

The aim of this study was to explore effects on anxiety-like behavior of $D_{1}$ dopamine receptor agonist, SKF-38393, and of $\mathrm{D}_{1}$ dopamine receptor antagonist, $\mathrm{SCH}-23390$, given alone or in combination with a low dose of $17 \beta$-estradiol $\left(17 \beta\right.$ - $\left.\mathrm{E}_{2}\right)$ to ovariectomized (OVX) rats. Two weeks after surgery, OVX rats began 14 days of treatment with the vehicle, a low dose of $17 \beta$ $\mathrm{E}_{2}\left(5.0 \mu \mathrm{g} / \mathrm{rat}\right.$, s.c.), SKF-38393 (0.1 mg/kg, i.p.), SCH-23390 (0.1 mg/kg, i.p.), SKF-38393 plus $17 \beta-\mathrm{E}_{2}$, or SCH- 23390 plus $17 \beta-$ $\mathrm{E}_{2}$. The animals were tested in the black and white model (BWM) and the open field test (OFT). SCH-23390 (0.1 mg/kg, i.p.) alone or in a combination with a low dose of $17 \beta-\mathrm{E}_{2}(5.0 \mu \mathrm{g} / \mathrm{rat}$, s.c.) resulted in anxiolytic-like effect in OVX rats in the BWM. Repeated treatment with SCH-23390 and $17 \beta-\mathrm{E}_{2}$ profoundly increased anxiolytic-like effect of single substances exerted per se. Coadministration of SCH-23390 with $17 \beta-\mathrm{E}_{2}$ increased frequency of rearing and grooming in OVX rats in OFT. SKF-38393 $(0.1 \mathrm{mg} / \mathrm{kg}$, i.p. $)$ treatment failed to alter anxiety-like behavior in OVX rats in the BWM. The results of the present study suggest that $17 \beta-\mathrm{E}_{2}$ and $\mathrm{SCH}-23390$ interact to exert anxiolytic-like action and that each of these drugs can potentiate effects of each other.

\section{Introduction}

Anxiety is an adaptive response which detects and prepares an individual against a real or a potential threat [1]. There is an extensive literature highlighting close relationship between anxiety-like behavior and the mesolimbic dopamine (DA) system $[2,3]$. Several preclinical and clinical data suggest that $\mathrm{DA}$, acting on $\mathrm{D}_{1}$-like receptors, is one of the most important neuromodulators of fear and anxiety [4]. $\mathrm{D}_{1}$-like receptors family is composed of two different receptor subtypes, the $D_{1}$ and $D_{5}$ receptors [1]. High numbers of $D_{1}$ receptors are located within caudate putamen $(\mathrm{CPu})$, nucleus accumbens $(\mathrm{NAc})$, and substantia nigra pars reticulata $(\mathrm{SNr})$ with a less dense distribution in the amygdaloid regions [5]. Evidences suggest that $\mathrm{D}_{1}$ receptors in the $\mathrm{CPu}, \mathrm{NAc}$, and $\mathrm{SNr}$ facilitate motivated behavior $[6,7]$, while those in the amygdala are more involved in affective behavior $[8,9]$.

It is well established that stress activates the DA system and increases extracellular DA in the nucleus accumbens septi and the medial prefrontal cortex, inducing anxiolyticlike behavioral effects [10-12]. Besides, dopaminergic mechanisms alter behavioral responses to naturally anxiogenic environmental stimuli $[3,13]$. In addition, both the DA system and anxiety-like behavior are dramatically altered by early-life stressors $[14,15]$ and withdrawal from chronic drug exposure $[16,17]$. There is also evidence that stress-induced increases in DA metabolism can be attenuated by antianxiety drugs, such as diazepam and ICS 205930 (tropisetron) [11, $18,19]$. Also, animal studies indicated anxiolytic-like effects of $\mathrm{D}_{1}$ receptor antagonists on anxiety-related behavior which are dependent on behavioral model of anxiety and route of treatment [20-22]. However, the neurobiological mechanisms governing these relationships have not been fully established yet.

On the other hand, the activity of the dopaminergic neurotransmitter system is sensitive to modulation by the ovarian steroids. Estrogen depletion induced by ovariectomy results in a marked decrease in dopaminergic cell density in the brain [23]; this effect can be reversed by estrogen administration in 14 days after ovariectomy. Estrogen administration in 14 days after ovariectomy was still able to change activity of dopaminergic neurons, whereas it lost this capability after longer period of estrogen depletion [23]. Thus, changes in 
the peripheral levels of estrogen are associated with those in the activity of DA system [24, 25]. Indeed, estrogen affects the concentration of dopamine in specific brain areas and induces rapid changes in the response of striatal neurons to $\mathrm{D}_{1}$ dopamine receptor agonists [3] possibly by producing uncoupling of the DA receptor-G protein complex [4]. Prolonged estrogen administration induces downregulation of dopamine activity $[23,26]$ and produces a dopamine receptor supersensitivity $[15,27,28]$ that results in a release from the inhibitory action of these receptors and enhancement of stimulated dopamine release. Estrogen also increased density of the dopamine reuptake protein [29, 30]. However, the mechanisms through which DA and estrogen signaling crosstalk and the role played by the DA receptor positive neurons still remain unclear.

The current experiment was conducted to clarify the effects of $\mathrm{D}_{1}$ receptor agonist/antagonist on anxiety-like behavior in ovariectomized rats on the black and white model (BWM). The BWM has been useful to screen substances with anxiolytic or anxiogenic potency [31] and to detect changes on anxiety-like indicators related with hormonal oscillations in cycling, pregnant, and lactating rats. This experimental model of anxiety is based on the innate preference of rats to explore a novel environment against their natural avoidance of a brightly illuminated open field. Thus, investigating the effects of dopaminergic drugs in the novel specific behavioral paradigm related to anxiety may lead to a greater understanding of the utility of DA and estrogen interaction in the mechanisms of anxiety disorders.

The main objective of this research is to study effects of $\mathrm{D}_{1}$ receptor agonist SKF-38393 and $\mathrm{D}_{1}$ receptor antagonist $\mathrm{SCH}-$ 23390 injected chronically for 14 days alone or in combination with $17 \beta$-estradiol $\left(17 \beta-\mathrm{E}_{2}\right)$ on anxiety-like behavior in adult OVX rats. In the study, OVX rats and OVX rats with administration of $17 \beta-\mathrm{E}_{2}$ were used.

\section{Methods}

2.1. Animals. A total number of 70 adult female rats of Wistar strain (purchased from Rappolovo, Saint Petersburg, Russia) weighing 180-200 g were used. For at least a week prior to the experiments, the rats were housed six in a cage under standard environmental conditions: constant temperature of $23 \pm 1^{\circ} \mathrm{C}, 60 \%$ humidity, $12 \mathrm{~h}$ light/dark cycle (light on 8:00 a.m.), food, and water ad libitum. All experiments were carried out in accordance with the guide for care and use of laboratory animals published by the National Institute of Health (National Research Council, publication 85-23, revised in 1996) and the Animal Welfare Assurance Renewal for I. P. Pavlov Institute of Physiology. The rationale, design, and methods of this study have been approved by the Ethical Committee for Animal Research, I. P. Pavlov Institute of Physiology. Experiments were carried out in a soundproof and air-regulated experimental room, to which animals were habituated, at least $30 \mathrm{~min}$ before each test.

2.2. Surgery. Ovariectomy was performed through an abdominal ventral incision under ethylic ether anesthesia.
The complete extraction of the ovaries was corroborated by visual inspection. After surgery, females were retrieved in a community cage with other rats. Efficiency of $17 \beta$ $\mathrm{E}_{2}$ administration to OVX rats was controlled by vaginal smears. The ovarian phase as diestrus in intact rats was also detected by vaginal smears using light microscopy based on the predominant cell type. OVX animals were allowed to have 2 weeks for postoperative recovery before administration of drugs. After two weeks, all OVX rats were randomly assigned to each of the experimental groups and subjected to treatment and behavioral testing.

2.3. Drugs and Treatment. $\mathrm{D}_{1}$ receptor agonist, SKF-38393 hydrochloride, purchased from Sigma (D-047, Sigma Chemical Co., USA) and $\mathrm{D}_{1}$ receptor antagonist, SCH-23390, purchased from Sigma (D-054, Sigma Chemical Co., USA) were dissolved in sterile saline $(0.9 \%)$. The estrogen $17 \beta$ $E_{2}$, purchased from Sigma (E-8875, Sigma Chemical Co., USA), was dissolved in sterile sesame oil. All solutions were freshly prepared before each experimental series. Rats received SKF-38393 in dose of $0.1 \mathrm{mg} / \mathrm{kg}$, i.p., SCH-23390 in dose of $0.1 \mathrm{mg} / \mathrm{kg}$, i.p., and $17 \beta-\mathrm{E}_{2}$ in dose of $5.0 \mu \mathrm{kg} / \mathrm{rat}$, s.c. All preparations were chronically injected for 14 days once daily. Drugs were administered in 2 weeks after postoperative period following ovariectomy. Saline was injected i.p. to control 1 (intact rats) with the same procedure. Control 2 (OVX rats) received oil solvent injection in the same volume. All animals were gently handled by experienced keepers from the facility each day for a week prior to experimental procedures. Any environmental or physical stress was avoided in order to habituate the rats to manipulation. Rats subjected to drug or saline administration received an injection volume of $0.1 \mathrm{~mL}$. All behavioral experiments were carried out in $45 \mathrm{~min}$ after the last injection of drug.

2.4. Experimental Design. OVX rats were divided into seven groups of 10 animals in each for performance of behavioral tests. Animals used for black and white model (BWM) and open field test (OFT) were the same. The two control groups constituted of intact rats in diestrus phase treated with saline i.p. (control 1) and OVX rats treated with oil solvent s.c. (control 2). The five other experimental groups were of OVX rats treated with $17 \beta-\mathrm{E}_{2}$; OVX rats injected with SKF-38393; OVX females injected with SCH-23390; OVX rats treated with SKF-38393 in combination with $17 \beta-\mathrm{E}_{2}$ in the same dose which was given to OVX rats; and OVX females treated with SCH-23390 daily in combination with $17 \beta-\mathrm{E}_{2}$ in the same dose which was applied to OVX females.

In a preliminary experiment, the dose-effect relationship of chronic administration of SKF-38393 or SCH-23390 to the OVX rats compared with placebo was studied in the locomotor activity test [32]. This experiment was carried out to verify test suitability in our experimental plan. For this reason, we selected three doses of SKF-38393 (0.05, 0.1 , and $0.2 \mathrm{mg} / \mathrm{kg}$ ) and SCH-23390 (0.05, 0.1, $0.2 \mathrm{mg} / \mathrm{kg})$ and found the $0.1 \mathrm{mg} / \mathrm{kg}$ dose for two drugs being fully inactive in changing the locomotor activity. This dose was selected for succeeding experiments. Furthermore, this dose 
was considered as the minimum behavioral doses for OVX rats in the locomotor activity test [32]. Thus, this dose of dopaminergic drugs was selected for the BWM and the OFT. Ovariectomy markedly decreases estrogen level and $17 \beta-\mathrm{E}_{2}$ receptor activity in the different structures of the brain [27, $28]$. In this connection, low dose of $17 \beta-\mathrm{E}_{2}$ may play a trigger role in activation of $17 \beta-\mathrm{E}_{2}$ receptor activity at hypoestrogenic syndrome [28]. Thus, we used a low dose of $17 \beta-\mathrm{E}_{2}$ in our present study. The low dose of $17 \beta-\mathrm{E}_{2}(5.0 \mu \mathrm{g} / \mathrm{rat}$, s.c.) was chosen from the studies performed by Estrada-Camarena and coworkers $[33,34]$.

\section{Behavioral Tests}

3.1. Black and White Model. The dimensions of the BWM were $80 \times 40 \times 40 \mathrm{~cm}$. The box was further divided into two equal chambers $(40 \times 40 \times 40 \mathrm{~cm})$ by a barrier possessing a doorway $(10 \times 10 \mathrm{~cm})$ that allowed the rats to cross freely from one chamber to the other. The black compartment was not illuminated, whereas the white compartment was completely illuminated by a $40 \mathrm{~W}$ white light. A video camera was installed above the illuminated compartment to record the rat activity in the box. Two independent observers later measured the behavioral variables. On the testing day, the rats were brought to the experimental room at 18:00 h (initiating the dark phase) and left for 1 hour to acclimatize to the novel surroundings. The BWM was initiated at 19:00 h, 1 hour after initiating the dark phase. After this time, the rat was placed into the middle of the black compartment facing the doorway and the rat behavioral activity was measured for $5 \mathrm{~min}$. The evaluated variables were latency to the first entry into the white compartment, time spent in the white compartment, and frequency of entries into the white compartment. After each test session, the BWM was carefully cleaned and deodorized with a cleaning solution (Vekton, Russia, composition is ammonia $0.5 \%$, ethanol $15 \%$, extran 10\%, isopropyl alcohol 5\%, citrus aromatizing 19\%, and distilled water $50.5 \%$ as v.v\%).

3.2. Open Field Test. To evaluate the effect of dopaminergic substances on spontaneous locomotor activity, grooming, and rearing, the rats were submitted to a $5 \mathrm{~min}$ period to the OFT. An opaque Plexiglas cage $(44 \times 33 \mathrm{~cm})$ with walls $20 \mathrm{~cm}$ in height was used. The floor was divided into 12 squares $(11 \times$ $11 \mathrm{~cm})$. A video camera was installed above the cage to record the activity of the rats. Two independent observers measured the behavioral variables. After each test session, the OFT was carefully cleaned and deodorized with a cleaning solution (Vekton, Russia, composition is ammonia $0.5 \%$, ethanol $15 \%$, extran 10\%, isopropyl alcohol 5\%, citrus aromatizing 19\%, and distilled water $50.5 \%$ as v.v\%).

3.3. Statistical Analysis. All data were analyzed using unvariate random design analysis of variance and the post hoc Dunnett's test for multiple comparisons. A $P$ value of 0.05 or less was considered as indicative of a significant difference. Where not indicated, ANOVA revealed no significant level of variance.

\section{Results}

4.1. Black and White Model. The post hoc test revealed the differences among the groups for anxiety-like behavior in the BWM $(P<0.0001)$. The OVX rats treated by oil solvent only (control 2) demonstrated the markedly decreased time into the white compartment as compared to the control intact rats (control 1; $P<0.05$; Figure 1(a)). The OVX rats given a low dose of $17 \beta-\mathrm{E}_{2}(5.0 \mu \mathrm{g} / \mathrm{kg})$ also spend more time into the white compartment as compared to the control groups 1 and 2 , indicating that $17 \beta-\mathrm{E}_{2}$ in low dose is an anxiolytic agent $(P<0.05)$ (Figure 1(a)). Simultaneously, OVX rats treated with SCH-23390 $(0.1 \mathrm{mg} / \mathrm{kg})$ significantly spend more time in the white compartment as compared with the control groups 1 and $2(P<0.05$, Figure $1(\mathrm{a}))$. Application of SCH-23390 in combination with a low dose of $17 \beta-\mathrm{E}_{2}$ in the OVX rats caused profoundly increase of the time into the white compartment (post hoc, versus control group 2 and OVX group treated with $\left.17 \beta-\mathrm{E}_{2}, P<0.05\right)$. Thus, the combined administration of SCH-23390 with a low dose of $17 \beta-\mathrm{E}_{2}$ to the OVX females enhanced the positive effects of each preparation on the anxiolytic-like behavior in the BWM.

In contrast, the $\mathrm{D}_{1}$ receptor agonist SKF-38393 alone or SKF-38393 in a combination with a low dose of $17 \beta-\mathrm{E}_{2}$ significantly reduced the time spent in the white compartment compared with the control rats $(P<0.05$, Figure 1(a)). Interestingly, OVX rats given SKF-38393 together with $17 \beta$ $\mathrm{E}_{2}$ demonstrated complete inhibition of the positive effect induced by $17 \beta-\mathrm{E}_{2}$ on anxiety-like behavior (post hoc, versus OVX group treated with $17 \beta-\mathrm{E}_{2}, P<0.05$ ).

The post hoc test revealed differences among the groups for anxiety-like behavior in the BWM $(P<0.05)$. The OVX rats treated by oil solvent only (control 2) demonstrated the markedly increased first entry into the white compartment as compared to the control intact rats (control 1; $P<$ 0.05 ; Figure $1(\mathrm{~b})$ ). The OVX rats given low dose of $17 \beta-\mathrm{E}_{2}$ $(5.0 \mu \mathrm{g} / \mathrm{kg})$ failed to modify the latency to the first entry into the white compartment as compared to control OVX rats $(P>0.05$, Figure $1(\mathrm{~b}))$. The OVX rats treated with $\mathrm{SCH}-$ $23390(0.1 \mathrm{mg} / \mathrm{kg})$ showed a significant decrease in the latency to the first entry into the white compartment compared with the OVX rats $(P<0.05$, Figure $1(\mathrm{~b}))$. The OVX rats given SCH-23390 plus $17 \beta-\mathrm{E}_{2}$ also demonstrated more decrease in the latency to the first entry into the white compartment (post hoc, versus OVX group and OVX group treated with $17 \beta-\mathrm{E}_{2}$, $P<0.05)$. The post hoc test showed that in OVX rats treated with SKF-38393 alone or SKF-38393 combined with $17 \beta-\mathrm{E}_{2}$, there was a significant increase in the latency to the first entry into the white compartment (post hoc, versus control intact group, OVX group, and OVX group treated with $17 \beta$ $\left.\mathrm{E}_{2}, P<0.05\right)$.

The post hoc test revealed differences among the groups for this parameter in the BWM $(P<0.05)$. The time spent in exploration towards the white compartment in the control OVX rats (control 2) was markedly decreased as compared to the control intact rats (control 1, Figure 2(a)). The OVX rats treated with $17 \beta-\mathrm{E}_{2}(5.0 \mu \mathrm{g} / \mathrm{kg})$ demonstrated a significant increase in the time spent in exploration towards the white compartment compared with the control OVX rats 


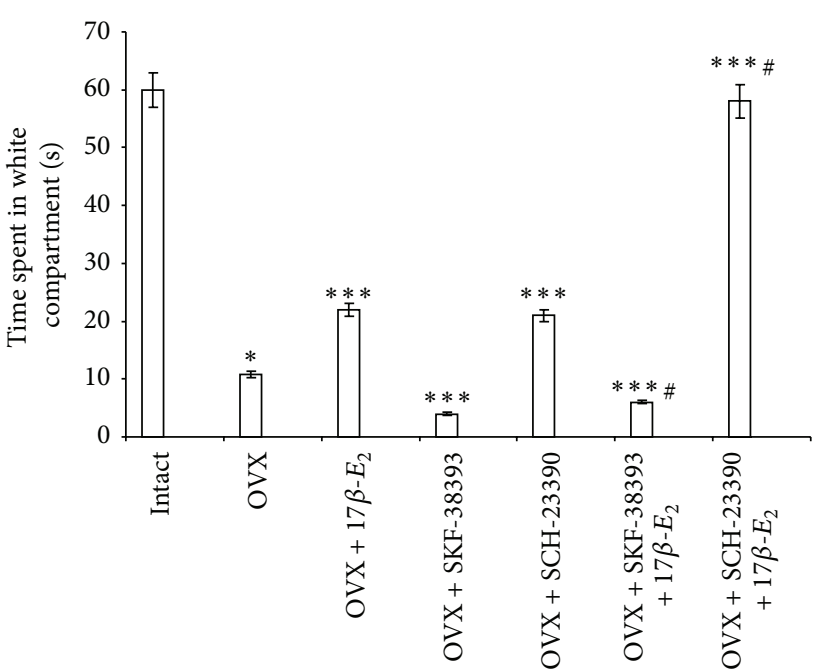

(a)

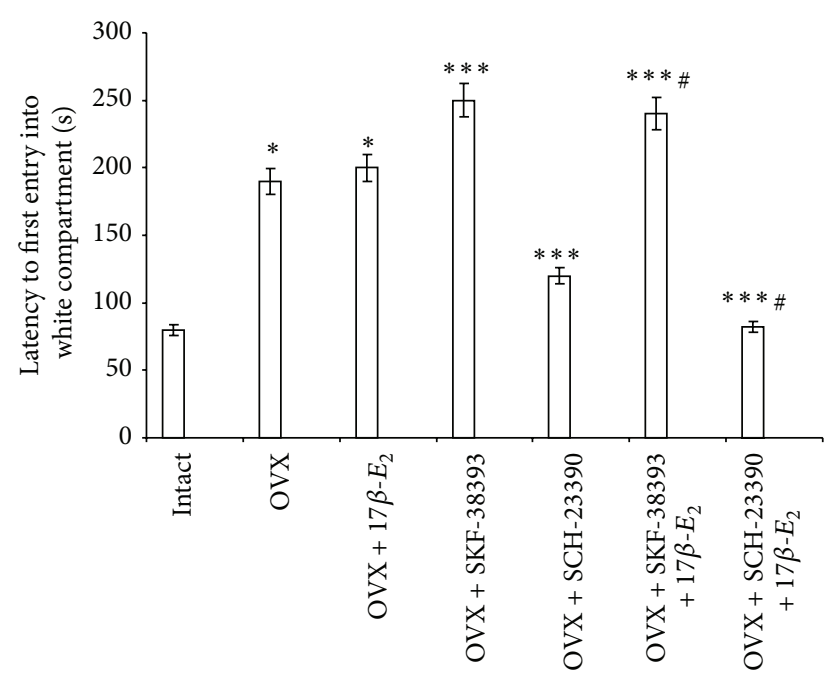

(b)

FIGURE 1: Effects of SKF-38393 (0.1 mg/kg, i.p.) and SCH-23390 (0.1 mg/kg, i.p.) on the anxiety-like behavior in OVX rats and OVX rats treated with low dose of $17 \beta-\mathrm{E}_{2}$ in the BWM. The time spent in white compartment (a) and the latency to first entry of experimental groups in the BWM. Columns represent the time spent in white compartment (a) as mean \pm SEM (in sec) and latency to first entry into white compartment (b) as mean \pm SEM (in sec). Each group was comprised of 10 rats. ${ }^{*} P<0.05$ versus control intact rats (control 1 ); ${ }^{* *} P<0.05$ versus control OVX rats (control 2); ${ }^{\#} P<0.05$ versus OVX rats treated with $17 \beta-\mathrm{E}_{2}$.

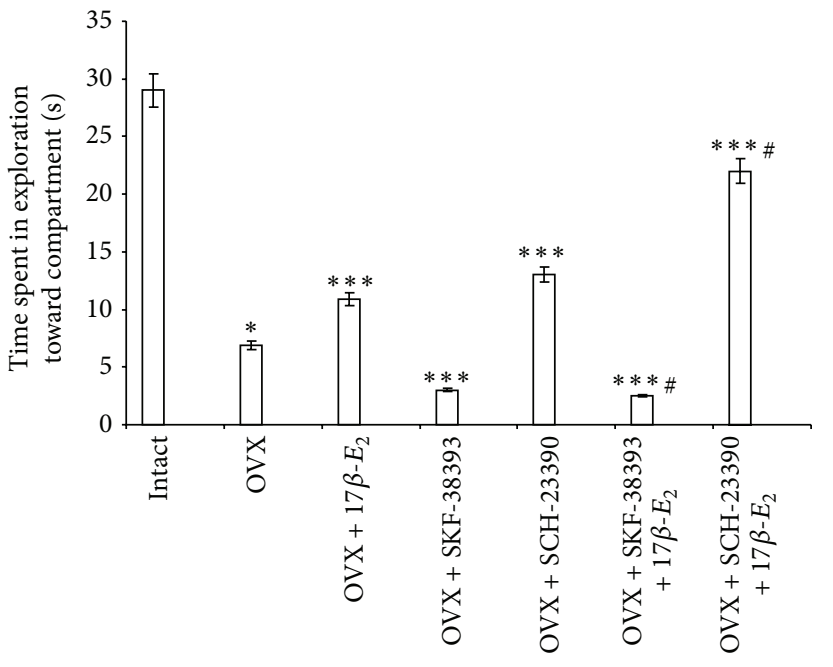

(a)

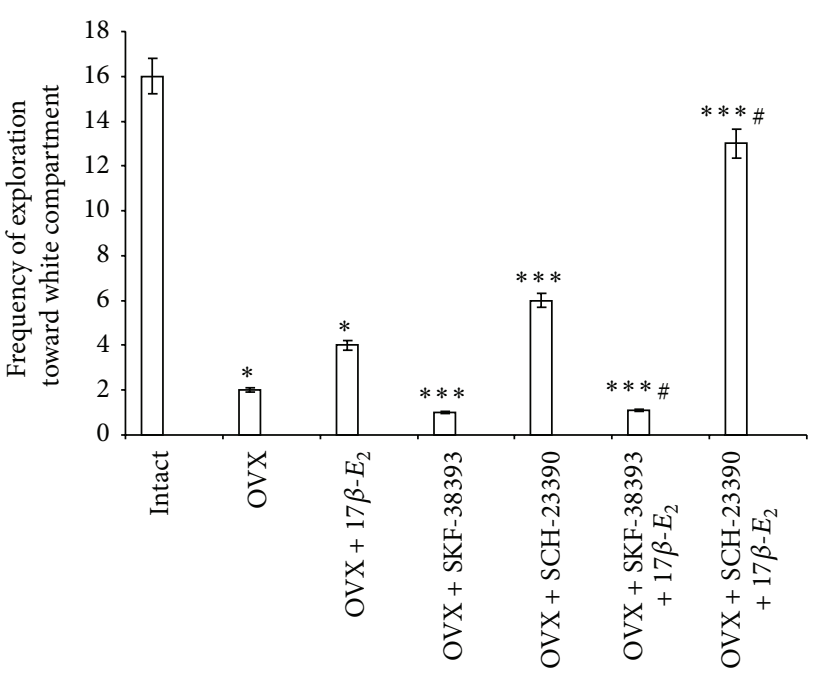

(b)

FIGURE 2: Effects of SKF-38393 (0.1 mg/kg, i.p.) and SCH-23390 (0.1 mg/kg, i.p.) on the anxiety-like behavior in OVX rats and OVX rats treated with low dose of $17 \beta-\mathrm{E}_{2}$ in the BWM. The time spent in exploration towards white compartment (a) and the frequency of explorations towards white compartment (b) of experimental groups in the BWM. Columns represent the time spent in exploration towards white compartment (a) as mean \pm SEM (in sec) and the frequency of explorations towards white compartment (b) as mean \pm SEM. Each group was comprised of 10 rats. ${ }^{*} P<0.05$ versus control intact rats (control 1$) ;{ }^{* *} P<0.05$ versus control OVX rats (control 2 ); ${ }^{*} P<0.05$ versus OVX rats treated with $17 \beta-\mathrm{E}_{2}$.

$(P<0.05)$, as compared to the control $2(P<0.05)$, but values of this parameter was significantly decreased as compared to the intact control group (Figure 2(a)). The post hoc test has revealed that OVX rats treated with SCH-23390 spent more time in exploration towards the white compartment as compared with the OVX rats $(P<0.05$, Figure $2(\mathrm{a}))$. $\mathrm{SCH}-23390$ in combination with $17 \beta-\mathrm{E}_{2}$ administered to the
OVX rats resulted in a profound increase in the time spent in exploration towards the white compartment (post hoc, versus control OVX group and OVX group treated with $17 \beta$ $\left.\mathrm{E}_{2}, P<0.05\right)$. Thus, the coadministration of SCH-23390 with a low dose of $17 \beta-\mathrm{E}_{2}$ to the OVX females improved effects of each preparation on anxiolytic-like behavior in the BWM. However, OVX rats treated with SKF-38393 
alone or SKF-38393 in combination with $17 \beta-\mathrm{E}_{2}$ exhibited a significant decrease in the time of exploration towards the white compartment compared with the OVX rats $(P<0.05$, Figure 2(a)). Interestingly, SKF-38393 administered with low dose of $17 \beta-\mathrm{E}_{2}$ in OVX rats completely blocked the positive effect of $17 \beta-\mathrm{E}_{2}$ on this parameter (post hoc, versus OVX group treated with $17 \beta$ - $\mathrm{E}_{2}, P<0.05$ ).

Similarly, the post hoc test revealed differences among the groups for this parameter in the BWM $(P<0.05)$. The frequency of explorations towards the white compartment in the control OVX rats (control 2) was markedly decreased as compared to the control intact rats (control 1, Figure 2(b)). The frequency of explorations towards the white compartment in OVX rats treated with a low dose of $17 \beta-\mathrm{E}_{2}(5.0 \mu \mathrm{g} / \mathrm{kg})$ was significantly increased as compared to the control $2(P<$ $0.05)$, but values of this parameter was significantly decreased as compared to the intact control group (Figure 2(b)). The OVX rats treated with $\mathrm{SCH}-23390$ displayed a significant increase in the frequency of explorations towards the white compartment compared with the control OVX rats $(P<$ 0.05 , Figure $2(\mathrm{~b}))$. The coadministration of SCH-23390 and $17 \beta-\mathrm{E}_{2}$ resulted in a profound increase of the frequency of explorations towards the white compartment (post hoc, versus control OVX group and OVX group treated with $17 \beta$ $\left.\mathrm{E}_{2}, P<0.05\right)$. Thus, coadministration of both preparations enhanced positive effects of SCH-23390 and low dose of $17 \beta-\mathrm{E}_{2}$ on anxiety-like behavior in the OVX females in the BWM. In contrast, the OVX rats treated with SKF-38393 alone or SKF-38393 plus low dose of $17 \beta-\mathrm{E}_{2}$ spent less time of exploration towards the white compartment compared to the control intact and OVX rats $(P<0.05$, Figure $2(\mathrm{~b}))$. Interestingly, coadministration of SKF-38393 and $17 \beta-\mathrm{E}_{2}$ to the OVX rats completely blocked the positive effect of $17 \beta-\mathrm{E}_{2}$ on this parameter (post hoc, versus OVX group treated with $\left.17 \beta-\mathrm{E}_{2}, P<0.05\right)$.

4.2. Open Field Test. The post hoc test revealed differences among the groups for behavior in the OFT $(P<0.05)$. The ovariectomy or application of $17 \beta-\mathrm{E}_{2}$ in a low dose $(5.0 \mu \mathrm{g} / \mathrm{kg})$ failed to modify behavioral reactions of OVX rats as compared to the intact control females in the OFT $(P>0.05$, Figure 3$)$. Neither SCH-23390 alone nor SCH23390 plus $17 \beta-\mathrm{E}_{2}$ led to change of crossing behavior in the OVX rats (post hoc, versus control group, OVX group, and OVX group treated with $17 \beta-\mathrm{E}_{2}, P>0.05$ ). However, the post hoc test revealed that OVX rats treated with $\mathrm{SCH}$ 23390 demonstrated a significant increase in the frequency of rearing and grooming as compared to the control intact and OVX rats $(P<0.05$, Figure 3$)$. Coadministration of $\mathrm{SCH}-$ 23390 with $17 \beta-\mathrm{E}_{2}$ resulted in higher frequency of rearing and grooming in the OVX rats (post hoc, versus control OVX group and OVX group treated with $17 \beta-\mathrm{E}_{2}, P<0.05$, Figure 3). On the contrary, administration of the $D_{1}$-receptor agonist, SKF-38393 alone, or SKF-38393 with low dose of $17 \beta-\mathrm{E}_{2}$ significantly enhanced crossing behavior (post hoc, versus control intact group, control OVX group, and OVX group treated with $17 \beta-\mathrm{E}_{2}, P<0.05$, Figure 3 ). We found that Neither SKF-38393 nor SKF-38393 plus $17 \beta-\mathrm{E}_{2}$ led to altered

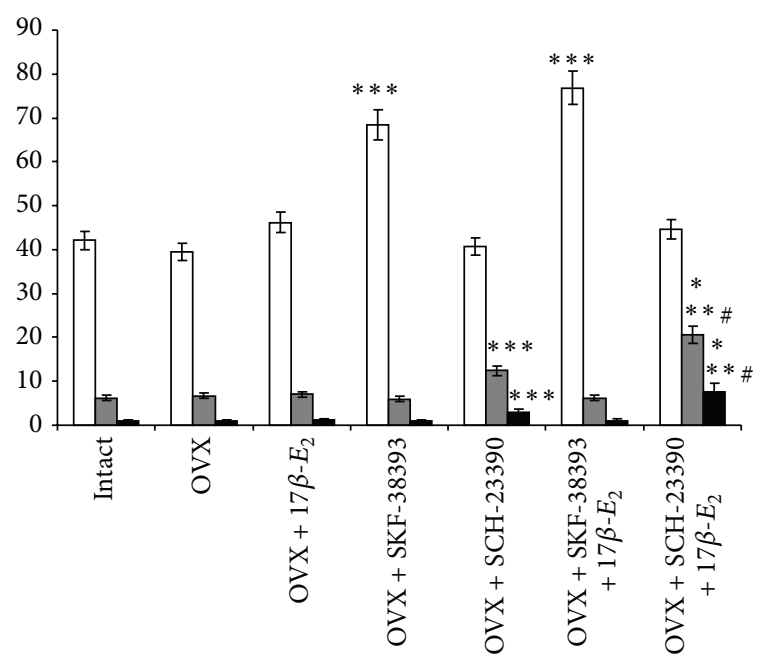

FIGURE 3: Effects of SKF-38393 (0.1 mg/kg, i.p.) and SCH-23390 $(0.1 \mathrm{mg} / \mathrm{kg}$, i.p.) on the behavior in OVX rats and OVX rats treated with low dose of $17 \beta-\mathrm{E}_{2}(5.0 \mu \mathrm{g} /$ rat, s.c.) in the open field test for $5 \mathrm{~min}$. Columns represent the behavioral parameters as mean \pm SEM. Light columns represent crossing, grey columns represent rearing, and dark columns represent grooming. Each group was comprised of 10 rats. ${ }^{*} P<0.05$ versus control intact rats (control $1) ;{ }^{* *} P<0.05$ versus control OVX rats (control 2$)$; ${ }^{\#} P<0.05$ versus OVX rats treated with $17 \beta-\mathrm{E}_{2}$.

rearing and grooming behavior in OVX rats in the OFT (post hoc, versus control intact group, control OVX group, and OVX group treated with $17 \beta-\mathrm{E}_{2}, P>0.05$, Figure 3 ).

\section{Discussion}

The main result of the present study was that SCH-23390 significantly decreased anxiety-related behavior in OVX rats treated with low dose of $17 \beta-\mathrm{E}_{2}$, suggesting that anxiolyticlike effect of SCH-23390 in the BWM is independent of the presence of $17 \beta-E_{2}$. However, it should be emphasized that combination of $\mathrm{SCH}-23390$ with a low dose of $17 \beta-\mathrm{E}_{2}$ is more effective for correction of anxiety-like behavior in the OVX rats. Also, the results of the present study demonstrated that a low dose of $17 \beta-\mathrm{E}_{2}$ was not effective on the latency to the first entry into the white compartment. One may assume that such dose of $17 \beta-\mathrm{E}_{2}$ is not enough for correction of this behavioral parameter. $17 \beta-\mathrm{E}_{2}$ has been reported to possess anxiolytic-like activity in animal models of anxiety, although the mechanism for such effect has not been fully established yet $[27,28]$. Some studies have demonstrated that $17 \beta-\mathrm{E}_{2}$ exerted an anxiolytic-like effect preferentially through the modulation of dopaminergic receptors $[35,36]$.

Since we aimed to detect anxiolytic-like effect of $\mathrm{SCH}$ 23390 and $17 \beta-\mathrm{E}_{2}$ coadministration, we selected a low dose of each drug to emphasize the synergistic effect of both preparations [33, 34]. Our results showed that $\mathrm{SCH}-23390$ $(0.1 \mathrm{mg} / \mathrm{kg}$, i.p. $)$ exerted a significant anxiolytic-like effect in the BWM. Intriguingly, we observed a profound anxiolyticlike activity in OVX rats treated with $\mathrm{SCH}-23390$ plus $17 \beta-\mathrm{E}_{2}$. To the best of our knowledge, there is no behavioral research 
for interaction of estrogen and SCH-23390 in anxiety-like behavior. The results of this study demonstrate that $17 \beta-\mathrm{E}_{2}$ and SCH-23390 interact to enhance anxiolytic-like efficacy.

Several lines of evidence suggest that DA is released in several brain regions such as the amygdala and the prefrontal cortex under stress conditions. By acting on $\mathrm{D}_{1}$ - or $\mathrm{D}_{2}$ like receptors, DA is involved in physiological processes subserving affective behaviors and emotional learning [4]. Biochemical studies have indicated that some anxiolytic drugs (diazepam and tropisetron) might attenuate stressinduced increase in DA metabolism [11, 18, 19]. Also, animal studies indicated anxiolytic-like effect of $\mathrm{D}_{1}$ receptor antagonists, such as SCH-23390 [1, 37, 38]. Some data suggest that selective $\mathrm{D}_{1}$ antagonists have anxiolytic-like effect in the EPM in mice, while stimulation of $D_{1}$ receptors prevents anxiolytic-like effect of $D_{1}$ antagonists as well as other agents $[39,40]$. Here, our present results are in good agreement with this data, showing that some dopaminergic drugs acting as DA receptor antagonists are also active as anxiolytics.

We did not find any dependence between effect of SKF38393 or SCH-23390 on anxiety-like behavior and effect of these drugs on locomotor activity. Since neither $17 \beta-\mathrm{E}_{2}$ nor SCH-23390 significantly influenced behavior in locomotor activity test, the anxiolytic-like synergy observed in the BWM cannot be attributed to altered motor activity. Data of the BWM and the locomotor test considered together indicate that interaction between $17 \beta-\mathrm{E}_{2}$ and $\mathrm{SCH}-23390$ is a mood effect rather than a motor effect. Thus, our results suggest that $\mathrm{D}_{1}$ receptor antagonist may possess anxiolytic-like activity as it was shown in some reports $[39,40]$.

Estrogen exerts a wide range of actions in the mammalian brain that extend far beyond its classical role as regulator of the hypothalamic-pituitary-gonadal axis [27, 28, 41]. These actions include neurotrophic effects, such as promotion of cell survival [42], modulation of synaptogenesis [28] and axonal and dendritic sprouting [23], and enhancement of neurogenesis $[27,28]$. In addition, estrogen modulates certain brain functions by affecting neurotransmitter levels within distinct neuronal populations as well as the expression of receptors and second messengers [24, 25]. Indeed, estrogen affects the concentration of dopamine in specific brain areas and induces rapid changes in the response of striatal neurons to $D_{1}$ and $D_{2}$ dopamine receptor agonists [43], possibly by producing an uncoupling of the $\mathrm{D}_{1}$ receptor- $\mathrm{G}$ protein complex [44]. Prolonged estrogen administration induces downregulation of presynaptic dopamine activity [30, 45] and produces a dopamine receptor supersensitivity [4548] that results in a release from the inhibitory action of these receptors and enhancement of stimulated dopamine release. Estrogen may, thus, increase activity of dopaminergic neurons through a combination of mechanisms, including a reduction in inhibitory control exerted by autoreceptors [45-48], an increase in activity of dopamine transporter [30], inhibition of $\mathrm{Ca}^{2+}$ influx [49], uncoupling of the $\mathrm{D}_{1}$ receptor$G$ protein complex [44], and modulation of neuronal plasticity $[42,50]$.

Currently, we do not know how exactly estrogen and DA modulate anxiety-related behavior. However, it is tempting

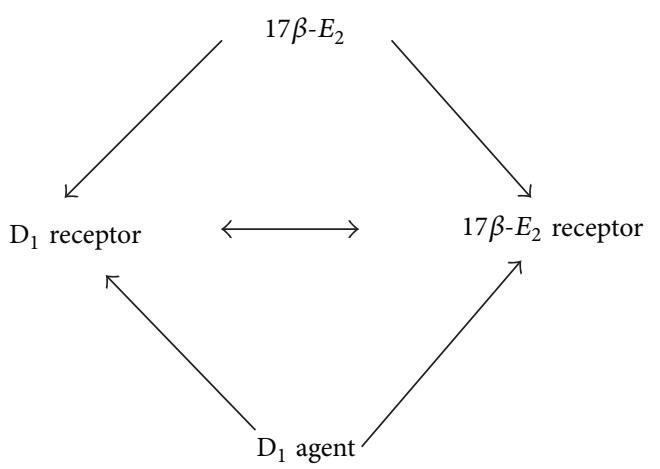

FIgURE 4: Possible mechanism of interaction between dopaminergic drug and $17 \beta-\mathrm{E}_{2}$.

to assume that a direct or indirect receptor-receptor interaction, via intracellular signaling pathways, might be involved. Effects of SCH-23390 application could be considered as part of estrogen withdrawal syndrome or manifestation of its genomic action. It can be assumed that low dose of $17 \beta-\mathrm{E}_{2}$ may directly influence both $17 \beta-\mathrm{E}_{2}$ receptor and $\mathrm{D}_{1}$ receptor (Figure 4). The precise mechanism by which SCH-23390 alone or in a combination with $17 \beta-\mathrm{E}_{2}$ induced positive effect on anxiety-like behavior remains to be established. Nevertheless, the present data add new facet to crosstalk between neurotransmitter dopaminergic and hormonal estrogen systems, within the framework of anxiety-related behavior. Estradiol likely has a stimulatory effect on the activity of dopaminergic neuronal system, playing a permissive role in SCH-23390 effect. Although it is not possible to assign specific role to estrogen in regulation of dopaminergic activity, observation that dopaminergic neurons are sensitive to a synergistic action of circulating steroid level provides a clue to understanding how fluctuations in ovarian hormone levels may amplify or ameliorate the symptomatology of psychiatric disorders characterized by altered mood and emotional states as well as the hypoestrogenic differences in drug sensitivity $[27,28]$.

The main interesting result from this study is that SKF38393 , selective $D_{1}$ receptor agonist, inhibited anxiolytic-like effect of $17 \beta-\mathrm{E}_{2}$ in BWM. Some evidence has shown that estrogen receptors (ERs) can be activated by dopaminergic ligands acting on $\mathrm{D}_{1}$ receptors $[26,41]$. One may assume that SKF-38393 prevents binding of $17 \beta-\mathrm{E}_{2}$ with ERs resulting in blockade of $17 \beta-\mathrm{E}_{2}$ positive action on anxiety-like behavior in OVX rats (Figure 4). Here, diverging effects of SKF-38393 and SCH-23390 in OVX rats can be related to changed metabolism of DA, expression of $\mathrm{D}_{1}$ receptors, expression of $17 \beta-\mathrm{E}_{2}$ receptors, and to their binding ability in the brain structures directly related to mood functions. There are a number of alternative possibilities worth considering.

In summary, $\mathrm{D}_{1}$ receptor antagonist, $\mathrm{SCH}-23390$, administered alone or in a combination with a low dose of $17 \beta-\mathrm{E}_{2}$ results in anxiolytic-like effect in OVX rats. Repeated treatment with SCH-23390 and low dose of $17 \beta-E_{2}$ profoundly enhanced anxiolytic-like effect the single substances per se. $D_{1}$ receptor agonist, SKF-38393, failed to modify anxietylike behavior in OVX rats in BWM. In addition, SKF-38393 
blocked anxiolytic-like effect of $17 \beta-\mathrm{E}_{2}$ in OVX rats. Further research is needed to elucidate the detailed mechanism by which SCH-23390 and $17 \beta-\mathrm{E}_{2}$ exert synergistic effect on anxiety-related behavior.

\section{Conflict of Interests}

The author declares that there is no conflict of interests regarding the publication of this paper.

\section{References}

[1] M. P. de la Mora, A. Gallegos-Cari, Y. Arizmendi-García, D. Marcellino, and K. Fuxe, "Role of dopamine receptor mechanisms in the amygdaloid modulation of fear and anxiety: structural and functional analysis," Progress in Neurobiology, vol. 90, no. 2, pp. 198-216, 2010.

[2] M. R. Diaz, A. M. Chappell, D. T. Christian, N. J. Anderson, and B. A. McCool, "Dopamine D3-like receptors modulate anxietylike behavior and regulate gabaergic transmission in the rat lateral/basolateral amygdala," Neuropsychopharmacology, vol. 36, no. 5, pp. 1090-1103, 2011.

[3] T. Kienast, A. R. Hariri, F. Schlagenhauf et al., "Dopamine in amygdala gates limbic processing of aversive stimuli in humans," Nature Neuroscience, vol. 11, no. 12, pp. 1381-1382, 2008.

[4] J. E. LeDoux, "Emotion circuits in the brain," Annual Review of Neuroscience, vol. 23, pp. 155-184, 2000.

[5] M. Savasta, A. Dubois, and B. Scatton, "Autoradiographic localization of D1 dopamine receptors in the rat brain with [3H]SCH 23390," Brain Research, vol. 375, no. 2, pp. 291-301, 1986.

[6] K. L. Nowend, M. Arizzi, B. B. Carlson, and J. D. Salamone, " $\mathrm{D}_{1}$ or $\mathrm{D}_{2}$ antagonism in nucleus accumbens core or dorsomedial shell suppresses lever pressing for food but leads to compensatory increases in chow consumption," Pharmacology Biochemistry and Behavior, vol. 69, no. 3-4, pp. 373-382, 2001.

[7] J. T. Trevitt, B. B. Carlson, K. Nowend, and J. D. Salamone, "Substantia nigra pars reticulata is a highly potent site of action for the behavioral effects of the D1 antagonist SCH 23390 in the rat," Psychopharmacology, vol. 156, no. 1, pp. 32-41, 2001.

[8] C. E. Macedo, R. C. R. Martinez, L. Albrechet-Souza, V. A. Molina, and M. L. Brandão, "5- $\mathrm{HT}_{2}$ and $\mathrm{D}_{1}$-mechanisms of the basolateral nucleus of the amygdala enhance conditioned fear and impair unconditioned fear," Behavioural Brain Research, vol. 177, no. 1, pp. 100-108, 2007.

[9] F. A. Guarraci, R. J. Frohardt, and B. S. Kapp, "Amygdaloid $D_{1}$ dopamine receptor involvement in Pavlovian fear conditioning," Brain Research, vol. 827, no. 1-2, pp. 28-40, 1999.

[10] S. Cabib and S. Puglisi-Allegra, "Opposite responses of mesolimbic dopamine system to controllable and uncontrollable aversive experiences," Journal of Neuroscience, vol. 14, no. 5, pp. 3333-3340, 1994.

[11] A. J. Dunn, "Stress-related activation of cerebral dopaminergic systems," Annals of the New York Academy of Sciences, vol. 537, pp. 188-205, 1988.

[12] B. B. Sherwin, "Estrogen and cognitive aging in women," Neuroscience, vol. 138, no. 3, pp. 1021-1026, 2006.

[13] M. J. Zuluaga, D. Agrati, M. Pereira, N. Uriarte, A. FernándezGuasti, and A. Ferreira, "Experimental anxiety in the black and white model in cycling, pregnant and lactating rats," Physiology and Behavior, vol. 84, no. 2, pp. 279-286, 2005.

[14] J. D. Higley, S. J. Suomi, and M. Linnoila, "CSF monoamine metabolite concentrations vary according to age, rearing, and sex, and are influenced by the stressor of social separation in rhesus monkeys," Psychopharmacology, vol. 103, no. 4, pp. 551$556,1991$.

[15] K. Matthews, J. W. Dalley, C. Matthews et al., "Periodic maternal separation of neonatal rats produces regionand gender-specific effects on biogenic amine content in postmortem adult brain," Synapse, vol. 40, pp. 1-10, 2001.

[16] U. Finckh, H. Rommelspacher, S. Kuhn et al., "Influence of the dopamine $\mathrm{D} 2$ receptor (DRD2) genotype on neuroadaptive effects of alcohol and the clinical outcome of alcoholism," Pharmacogenetics, vol. 7, no. 4, pp. 271-281, 1997.

[17] C. Nath, R. C. Saxena, and M. B. Gupta, "Effect of dopamine agonists and antagonists on the lorazepam withdrawal syndrome in rats," Clinical and Experimental Pharmacology and Physiology, vol. 27, no. 3, pp. 167-171, 2000.

[18] J. M. Finlay, M. J. Zigmond, and E. D. Abercrombie, "Increased dopamine and norepinephrine release in medial prefrontal cortex induced by acute and chronic stress: effects of diazepam," Neuroscience, vol. 64, no. 3, pp. 619-628, 1995.

[19] A. Imperato, S. Puglisi-Allegra, A. Zocchi, M. G. Scrocco, P. Casolini, and L. Angelucci, "Stress activation of limbic and cortical dopamine release is prevented by ICS 205-930 but not by diazepam," European Journal of Pharmacology, vol. 175, no. 2, pp. 211-214, 1990.

[20] B. Gao and M. G. Cutler, "Effects of quinpirole on the behaviour shown by mice in the light-dark box and during social interactions," Neuropharmacology, vol. 32, no. 1, pp. 93-100, 1993.

[21] A. A. Walf and C. A. Frye, "A review and update of mechanisms of estrogen in the hippocampus and amygdala for anxiety and depression behavior," Neuropsychopharmacology, vol. 31, no. 6, pp. 1097-1111, 2006.

[22] M. R. Zarrindast, N. Eslahi, A. Rezayof, P. Rostami, and M. Zahmatkesh, "Modulation of ventral tegmental area dopamine receptors inhibit nicotine-induced anxiogenic-like behavior in the central amygdala," Progress in Neuro-Psychopharmacology \& Biological Psychiatry, vol. 5, pp. 11-17, 2013.

[23] C. Leranth, R. H. Roth, J. D. Elswoth, F. Naftolin, T. L. Horvath, and J. Redmond D.E., "Estrogen is essential for maintaining nigrostriatal dopamine neurons in primates: implications for Parkinson's disease and memory," Journal of Neuroscience, vol. 20, no. 23, pp. 8604-8609, 2000.

[24] J. B. Becker, "Direct effect of $17 \beta$-estradiol on striatum: sex differences in dopamine release," Synapse, vol. 5, no. 2, pp. 157-164, 1990.

[25] J. B. Becker, "Gender differences in dopaminergic function in striatum and nucleus accumbens," Pharmacology Biochemistry and Behavior, vol. 64, no. 4, pp. 803-812, 1999.

[26] S. K. Mani, J. D. Blaustein, and B. W. O’Malley, "Progesterone receptor function from a behavioral perspective," Hormones and Behavior, vol. 31, no. 3, pp. 244-255, 1997.

[27] A. Markou, T. Duka, and G. M. Prelevic, "Estrogens and brain function," Hormones, vol. 4, no. 1, pp. 9-17, 2005.

[28] B. McEwen, "Estrogen actions throughout the brain," Recent Progress in Hormone Research, vol. 57, pp. 357-384, 2002.

[29] T. Di Paolo, P. Falardeau, and M. Morissette, "Striatal D-2 dopamine agonist binding sites fluctuate during the rat estrous cycle," Life Sciences, vol. 43, no. 8, pp. 665-672, 1988. 
[30] M. Morissette and T. Di Paolo, "Sex and estrous cycle variations of rat striatal dopamine uptake sites," Neuroendocrinology, vol. 58, no. 1, pp. 16-22, 1993.

[31] M. Bourin and M. Hascoët, "The mouse light/dark box test," European Journal of Pharmacology, vol. 463, no. 1-3, pp. 55-65, 2003.

[32] J. Fedotova and N. Ordyan, "Involvement of $\mathrm{D}_{1}$ receptors in depression-like behavior of ovariectomized rats," Acta Physiologica Hungarica, vol. 98, no. 2, pp. 165-176, 2011.

[33] E. Estrada-Camarena, A. Fernández-Guasti, and C. LópezRubalcava, "Antidepressant-like effect of different estrogenic compounds in the forced swimming test," Neuropsychopharmacology, vol. 28, no. 5, pp. 830-838, 2003.

[34] E. Estrada-Camarena, A. Fernández-Guasti, and C. LópezRubalcava, "Interaction between estrogens and antidepressants in the forced swimming test in rats," Psychopharmacology, vol. 173, no. 1, pp. 139-145, 2004.

[35] V. Harsh, S. Meltzer-Brody, D. R. Rubinow, and P. J. Schmidt, "Reproductive aging, sex steroids, and mood disorders," Harvard Review of Psychiatry, vol. 17, no. 2, pp. 87-102, 2009.

[36] W. Zhou, K. A. Cunningham, and M. L. Thomas, "Estrogen regulation of gene expression in the brain: a possible mechanism altering the response to psychostimulants in female rats," Molecular Brain Research, vol. 100, no. 1-2, pp. 75-83, 2002.

[37] B. Costall, C. A. Hendrie, M. E. Kelly, and R. J. Naylor, "Actions of sulpiride and tiapride in a simple model of anxiety in mice," Neuropharmacology, vol. 26, no. 2-3, pp. 195-200, 1987.

[38] E. M. Pich and R. Samanin, "Disinhibitory effects of buspirone and low doses of sulpiride and haloperidol in two experimental anxiety models in rats: possible role of dopamine," Psychopharmacology, vol. 89, no. 1, pp. 125-130, 1986.

[39] A. M. Becerra Garcia, R. Martinez, M. L. Brandão, and S. Morato, "Effects of apomorphine on rat behavior in the elevated plus-maze," Physiology and Behavior, vol. 85, no. 4, pp. 440-447, 2005.

[40] P. Simon, C. Panissaud, and J. Costentin, "Anxiogenic-like effects induced by stimulation of dopamine receptors," Pharmacology Biochemistry and Behavior, vol. 45, no. 3, pp. 685-690, 1993.

[41] J. D. Blaustein, "Minireview: neuronal steroid Hormone receptors: they're not just for hormones anymore," Endocrinology, vol. 145, no. 3, pp. 1075-1081, 2004.

[42] A. N. Talalaenko, I. A. Abramets, Y. V. Stakhovskii, A. A. Shekhovtsov, A. V. Chernikov, and S. L. Shevchenko, "The role of dopaminergic mechanisms of the brain in various models of anxious states," Neuroscience and Behavioral Physiology, vol. 24, no. 3, pp. 284-288, 1994.

[43] M. Febo, L. A. González-Rodríguez, D. E. Capó-Ramos, N. Y. González-Segarra, and A. C. Segarra, "Estrogen-dependent alterations in $\mathrm{D}_{2} / \mathrm{D}_{3}$-induced $\mathrm{G}$ protein activation in cocainesensitized female rats," Journal of Neurochemistry, vol. 86, no. 2, pp. 405-412, 2003.

[44] D. E. Dluzen, "Unconventional effects of estrogen uncovered," Trends in Pharmacological Sciences, vol. 26, no. 10, pp. 485-487, 2005.

[45] T. Di Paolo, A. Dupont, and M. Daigle, "Effect of chronic estradiol treatment on dopamine concentrations in discrete brain nuclei of hypophysectomized female rats," Neuroscience Letters, vol. 32, no. 3, pp. 295-300, 1982.

[46] T. Di Paolo, P. Poyet, and F. Labrie, "Effect of chronic estradiol and haloperidol treatment on striatal dopamine receptors,"
European Journal of Pharmacology, vol. 73, no. 1, pp. 105-106, 1981.

[47] R. E. Hruska and E. K. Silbergeld, "Increased dopamine receptor sensitivity after estrogen treatment using the rat rotation model," Science, vol. 208, no. 4451, pp. 1466-1468, 1980.

[48] R. E. Hruska, "Elevation of striatal dopamine receptors by estrogen: dose and time studies," Journal of Neurochemistry, vol. 47, no. 6, pp. 1908-1915, 1986.

[49] P. G. Mermelstein, J. B. Backer, and D. J. Surmeier, "Estradiol reduces calcium currents in rat neostriatal neurons via a membrane receptor," Journal of Neuroscience, vol. 16, no. 2, pp. 595-604, 1996.

[50] T. L. Thompson and R. L. Moss, "Modulation of mesolimbic dopaminergic activity over the rat estrous cycle," Neuroscience Letters, vol. 229, no. 3, pp. 145-148, 1997. 

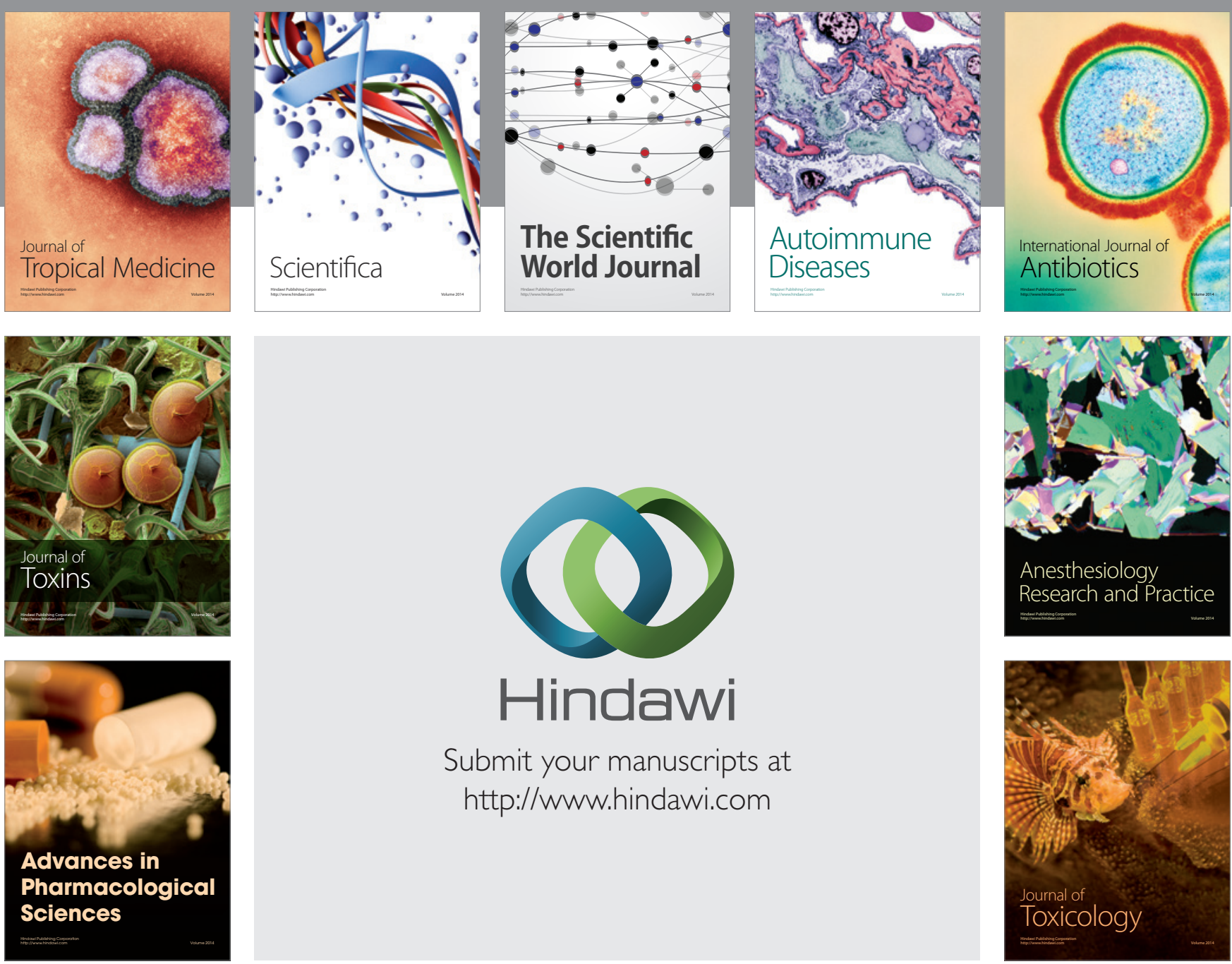

\section{Hindawi}

Submit your manuscripts at

http://www.hindawi.com
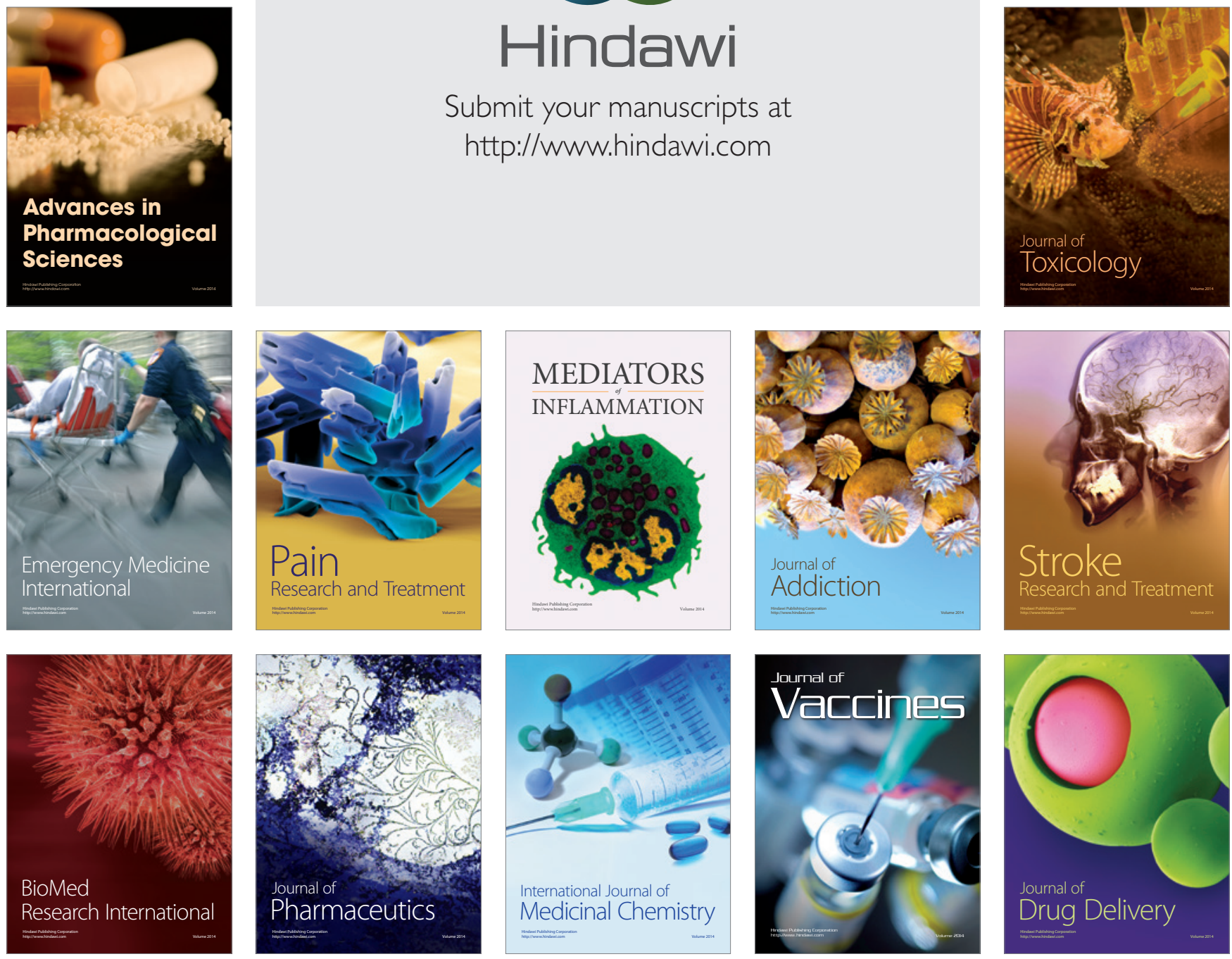